\title{
Working Time Configuration in Hospitals Using Personnel-oriented Simulation
}

\author{
Gert Zülch, Patricia Stock, and Jan Hrdina \\ ifab-Institute of Human and Industrial Engineering, University of Karlsruhe \\ Kaiserstrasse 12, D-76131 Karlsruhe, Germany, \\ WWW home page: http://www.ifab.uni-karlsruhe.de
}

\begin{abstract}
Current developments in Germany have led to severe consequences for the configuration of working times of medical and nursing personnel in hospitals. They underline the necessity to arrange work processes and personnel employment as efficiently as possible. In this context, the current project „Process Optimization and Efficient Personnel Employment in Hospitals“ has set the goal of developing a simulation-based procedure for the analysis of working time model. This procedure shall which can be used to explore the advantages and possibilities of working time models in hospitals based on simulation investigations and to derive configuration recommendations. The flexible alignment of the personnel capacity with the capacity requirements for patient treatment is used to achieve a high degree of patient-oriented service in medical tasks in order to help hospitals efficiently employ available personnel resources as well as to realize personnel-oriented goals. This article will introduce the developed concept for a simulation-based configuration of working times.
\end{abstract}

\section{Hospitals as Patient-oriented Enterprises}

In 2001 hospitals in Germany account for approximately 62 bn Euro and $1.1 \mathrm{~m}$ employed persons ([1], pp. 13). In comparison to production enterprises or other service areas, hospitals are characterized by several structural particularities:

- The operating hours for hospitals are generally 24 hours a day and seven days a week. Additionally, a great deal of night-work must be carried out.

- As in other service industries, the workload fluctuates greatly since it is primarily determined by the stochastic arrival of patients. Furthermore, the patients must usually be treated immediately.

- Furthermore, decisions regarding treatment are often made based on incomplete information, causing operations to be highly individual and very difficult to plan.

Please use the following format when citing this chapter:

Zülch G., Stock, P. and Hrdina, J., 2008, in IFIP International Federation for Information Processing, Volume 257, Lean Business Systems and Beyond, Tomasz Koch, ed.; (Boston: Springer), pp. 493-501. 
- In comparison to production enterprises and many other service industries, which are dominated by organizational goals, patient-oriented goals are of primary concern in h ospitals

- The occupational health and safety as well as hygiene requirements of the medical and nursing personnel must be taken into account during treatment workflows.

In addition to these general conditions, hospitals have recently been experiencing serious changes, which are above all affected by three developments:

- Since 01.01.2004 the German hospital financing is a fixed-price system based on the "German Diagnosis Related Groups" (G-DRGs), in which only a fixed amount per patient case is paid by the health insurances under public law. The hospitals are thus forced to work in a highly cost-efficient and transparent manner in order to cope with the ever-increasing cost pressure. Therefore, the costs optimization of the personnel area of a hospital has a significant impact on the hospital's total costs since at least two thirds thereof can be ascribed to this area (cf. [2], p. 389).

- Since 31.08.2005 the hospitals are forced by legal regulations to provide quality reports. This leads to the necessity for internal an external quality assurance, often connected with the implementation of quality management systems. Therefore, the analysis of treatment processes as well as the revelation of rationalization potential in traditional hospital processes is gaining in significance.

- The European Court of Justice declared in its judgement from 09.09.2003 (C151/02) that the guideline 93/104/EG of the European Council is to be interpreted that the stand-by duty of a doctor served by personal presence in the hospital represents in its entirety working time, even if said doctor is allowed, in times when he is not employed, to rest at his workplace. Since this decision the German working time law (Arbeitszeitgesetz - ArbZG) no longer corresponds with the cited EU guideline. This judgement has considerable effects on hospitals: Studies from the associations concerned assume that this creates a workforce deficit of 20,300 doctors and 12,900 other positions (all full-time) at least ([3], p. 9). This underlines the necessity to configure personnel employment more efficiently.

As a result of these far-reaching changes, hospitals find themselves confronted with fundamentally new organizational challenges. In order to meet the future challenges, hospitals must continue to redesign their structures and medical operations (cf. [4], p. 776). The same is true for the traditional working time configuration (i.e. shift and block models), which must be replaced by a more flexible and efficient task-oriented management of working time. The implementation of flexible working time models and their compliance with legal regulations represent one major prerequisite for the future alignment of personnel capacity and personnel requirements, since only then can patient-orientation and an economical personnel employment be achieved simultaneously (cf. e.g. [5], p. 43). 


\section{Problems in Working Time Configuration}

Various general conditions must be taken into account in the configuration of appropriate working time models, in particular legal provisions, wage agreements, ergonomic recommendations as well as hospital-, patient-, and employee-oriented objectives, which are often competing ([6], p. 52). These result in numerous alternatives or complementary applicable working time models. Thus, no "ideal" working time model exists, rather a working time model must be aligned with the specific legal, operational and personnel needs of each hospital department (cf. e.g. [7], p. 117). The addressed general conditions can even change over time (as has recently been the case in the hospital field; see chapter 1), thus creating the need for a periodic evaluation of the adequacy of a working time model.

Traditional static planning and assessment methods (e.g. benefit analyses and sensitivity analyses) only provide subjective statements regarding the expected effects of working time systems since their results are dependent upon the specific knowledge of the evaluator ([8], pp. 42). Furthermore, conventional assessment procedures do not sufficiently consider employee-related target criteria and in particular do not provide a prognosis of the expected stress that be imposed on the employees in certain working time models in hospitals with a fluctuating patient frequency (following [8], p. 52). In contrast to the conventional assessment methods, a dynamic analysis in a simulation model can provide comprehensive and prospective information regarding possible effects - both positive and negative - of envisaged working time models ([8], p. 53).

For this purpose, personnel-oriented simulation can be used for prospective evaluation. This approach has already proven to be highly effective in other fields of planning and assessment of work organization ([9], p. 371). Since the parameters of a working time configuration can be varied in a simulation model in nearly every possible combination, an efficient analysis and assessment of various working time models is thus made possible.

\section{Simulation-based Working Time Configuration}

For these reasons, the ifab-Institute for Human and Industrial Engineering of the University of Karlsruhe (Germany) has developed a simulation-based procedure with which working time models in hospitals can be assessed in an objective, efficient and quantitative manner. Several concepts have been developed for modelling and assessment, which are elucidated in the following (see Fig. 1).

\subsection{Modelling Concept for Working Time Models}

First, a modelling concept for the working time models relevant to the hospital area was developed. This concept was conceived to be capable of representing in particular working time models with on-call duty as well as flexible working time mod- 
els. Many authors differentiate working time into two components following Teriet ([10], p. 10), namely

- chronology, meaning the placement and distribution of working times, and

- chronometry, the duration or volume of working time.

This principle was incorporated into the simulation procedure for working time configuration (e.g. see $[11,12])$ and was refined for the hospital field of application (see Tab. 1; cf. also [8], pp. 55).

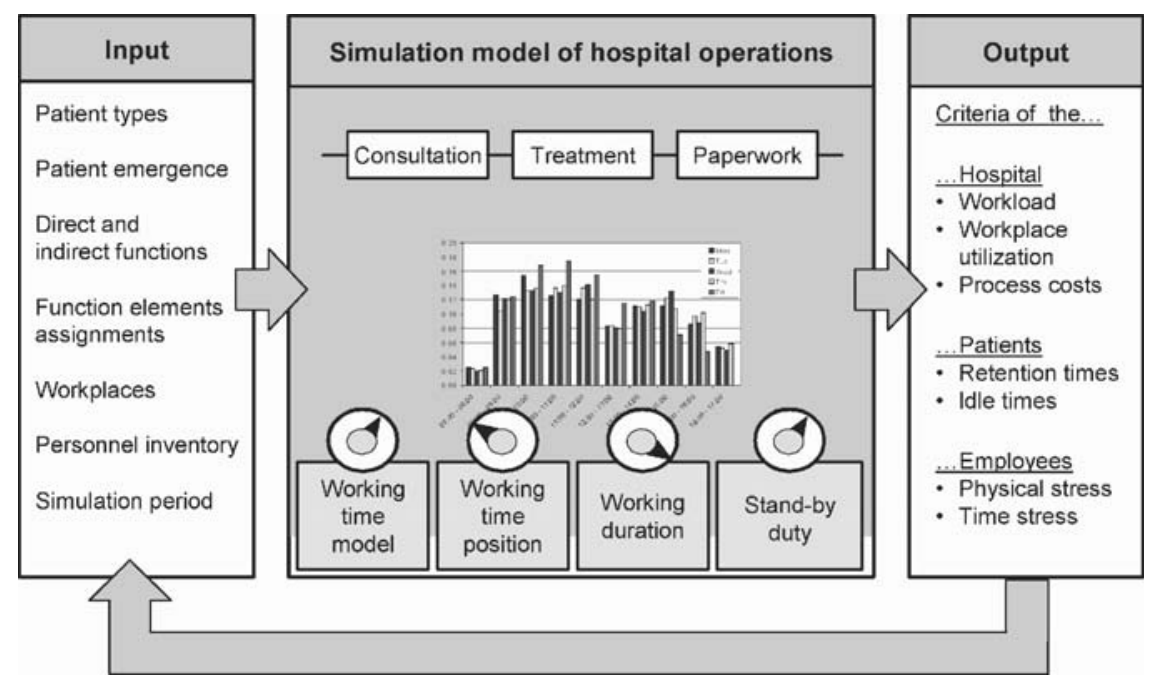

Fig. 1. Simulation of working time models for a hospital

Table 1. Modelling concept for working time models

\begin{tabular}{|c|c|}
\hline Content configuration elements & Formal configuration elements \\
\hline - Duration: & - Reference time frame \\
\hline $\begin{array}{l}\text { - Weekly working time in hours } \\
\text { - Minimum possible daily working } \\
\text { time }\end{array}$ & $\begin{array}{l}\text { - Implementation time frame in days, } \\
\text { meaning the time for which the } \\
\text { working time model is valid }\end{array}$ \\
\hline $\begin{array}{l}\text { in hours } \\
\text { Maximum possible daily working } \\
\text { time in hours }\end{array}$ & $\begin{array}{l}\text { Compensation time frame in days, } \\
\text { meaning the time in which the } \\
\text { contractually agreed working time }\end{array}$ \\
\hline - Placement: & must be performed \\
\hline $\begin{array}{l}\text { Number of working time corridors, } \\
\text { meaning tuples with starting and } \\
\text { ending times as well as }\end{array}$ & $\begin{array}{l}\text { - Planning time frame in days, } \\
\text { meaning the time in which the } \\
\text { employment times for each employee }\end{array}$ \\
\hline $\begin{array}{l}\text { availabilities } \\
\text { and possible } \quad \text { compensation }\end{array}$ & $\begin{array}{l}\text { of the organizational unit/organization } \\
\text { are defined and binding }\end{array}$ \\
\hline
\end{tabular}
bonuses

- Cycle period in days 
This modelling concept takes two aspects into account which are typical for hospitals:

- Hospitals often work with on-call duty. Therefore, the availability of on employee can be described with the following values:

- Regular working time,

- Work readiness, which forces the employee to stay on location of their employment (e.g. in the emergency room),

- Stand-by duty, which forces the employee to stay at a location specified by his employer (e.g. in the rest room) in order to take-up his employment immediately, and

- On-call duty, which allows the employee to choose his inhabitancy on his own as long as he is available in order to take-up his employment shortly.

- Wage agreements provide for varying compensation for night- and Sunday-shifts and also often for the compensation of overtime or various types of on-call duty. This can occur as a percentage or as a bonus, sometimes in combination.

Both individual working time models and even working time systems (meaning all the working time models implemented in an organizational unit/organization) can be described using these configuration elements. This takes the fact into account that, in practice, various working time models (e.g. differentiated for medical and nursing service or for various groups of practitioners) may be used within a hospital (or even within a hospital department).

\subsection{Modelling Concept for Hospitals}

Furthermore, a concept for modelling hospitals was developed. As a basis, the schemes developed by Heitz ([13], pp. 94) and Bogus ([8], pp. 102) for the description of manufacturing structures and service enterprises respectively have been used. The purely manufacturing- and service-specific attributes had to be eliminated from this scheme and supplemented with attributes for the description of hospital-specific requirements. The adjusted description scheme for hospitals includes the following elements:

- Patient structure and arrival patterns:

- Patient type

(characterized by the work operations to be carried out and their flow)

- Patient arrival (characterized by the distribution of the arrival patterns per patient type)

- Functions:

- Direct functions, meaning functions to be carried out specifically for a patient type (e.g. diagnosis or changing of bandages)

- Indirect functions, meaning functions that are not carried out for the patients directly, rather usually of preparatory or wrap-up nature or carried out for several patients in common

(e.g. preparation for the medicine distribution, shift hand-over, ward rounds)

- Resources:

- Workplaces (e.g. treatment rooms, operating theatres)

- Personnel (the workers employed and their qualifications) 
- Equipment (e.g. medical devices)

- Material (e.g. medicine, medical supplies)

\subsection{Evaluation Concept for Simulated Work Systems}

Finally, a hospital-specific assessment concept was developed. The concept should include a system of meaningful key figures which are independent from each other while also being nondimensional and standardized. The assessment concept based on degrees of goal achievement (cf. e.g. [14], pp. 69), which has already proven to be advantageous in the assessment of simulation models (cf. e.g. [13], pp. 97; [8], pp. 126) was drawn upon for this reason. A degree of goal achievement can assume a value between $0 \%$ and $100 \%$, where $100 \%$ represents the ideal value of the assessment figure.

The assessment is carried out analogously to reality, in part with business management and financial key figures (e.g. service rate, duration of patient stay, patient handling costs, utilization of resources, simulated used capacity costs). In addition, also some employee-related criteria concentrating on the imposed stress were defined (e.g. degree of physical stress and time stress). These key figures were derived from existing assessment concepts from the manufacturing ([13], pp. 97) and service fields ([8], pp. 126). However, further hospital-specific figures still need to be developed. These comprise (following [15], p. 31) patient-related key figures, such as e.g. waiting times until a planned treatment, deviation from planned and simulated execution times or the degree of adherence to visiting hours on the one hand, as well as key figures regarding the quality of care, e.g. uncompleted tasks on the other hand.

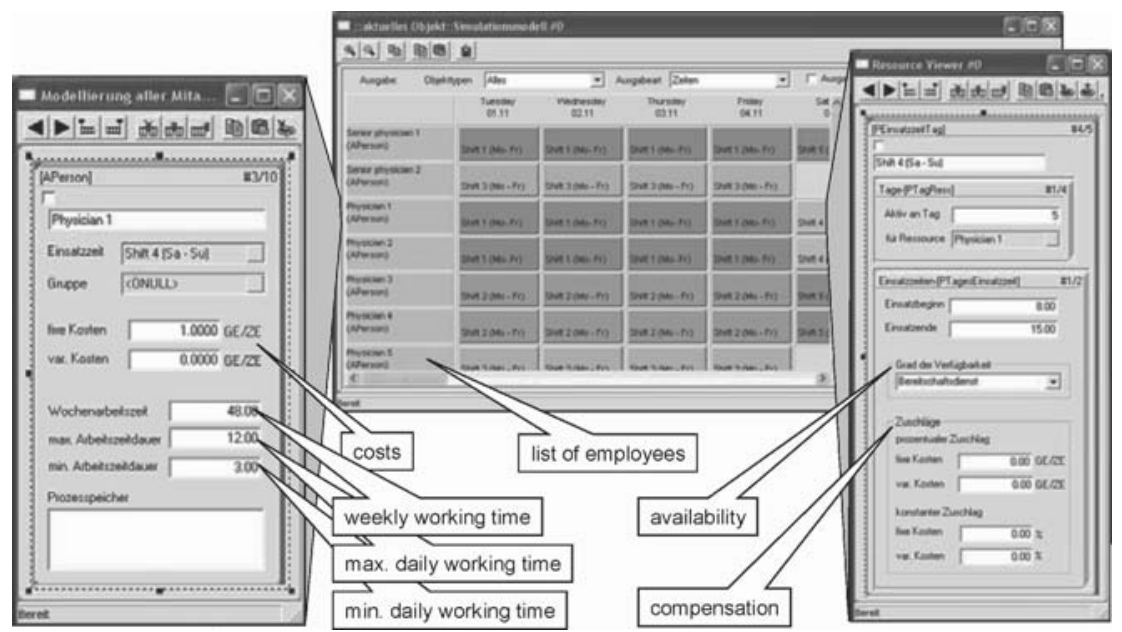

Fig. 2. Screenshot of the working times of one employees 


\section{The Simulation Procedure OSim-GAM}

The modelling concept described here was integrated into the ifab-developed objectoriented simulation procedure OSim (Object simulator; $[9,16]$ ), resulting in the simulation procedure OSim-GAM (Object simulator for working time configuration; [8]) for the analysis of working time models. In particular, each modelled employee or personnel type can be allocated to an individual working time model (see Fig. 2).

The modelling of the patient types is carried out using throughput diagrams in which the temporal-logistic dependencies of the patient treatment operations are represented in a type of network diagram. A throughput diagram can be triggered either by internal or external events, e.g. the stochastic arrival of a patient. A hospital can thus be described by the pattern of incoming patients and the available personnel, workplaces and equipment as well as by the set of all throughput diagrams. As a trigger to initialize a throughput diagram the intermediate arrival times per patient type are used. Figure 3 shows an example of such a throughput diagram as well as its trigger. The ambulant patient type modelled therein requires a sequence of four work operations (examination, therapy, consultation, administration) whose execution times are subject to a beta distribution. The trigger describes the arrival of one patient belonging to this patient type.

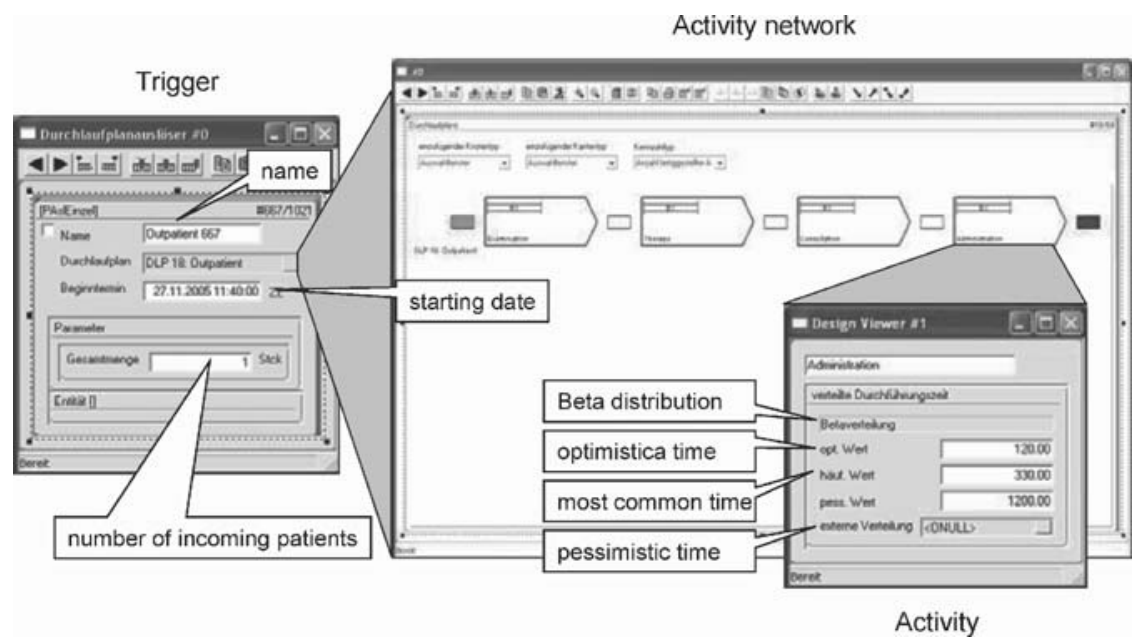

Fig. 3. Patient type and typical treatment illustrated through the example of an ambulant patient

\section{Summary and Outlook}

Working time configuration has proven to be an extremely complex problem, whose solution is influenced by myriad general conditions. In particular in hospitals, specific working time models are necessary. Prevalent assessment procedures only provide subjective results. For this purpose, the existing simulation procedure OSim$G A M$ was furthered for the objective and quantitative analysis of working time models in the hospital area. 
Simulation studies are currently being carried out in hospitals cooperating in this Project, which is supported by the German Research Association (DFG - Deutsche Forschungsgemeinschaft). The aim of theses studies is to verify the effectiveness of the procedure and to examine the effects of various working time models and systems on the defined goal criteria of the assessment concept.

\section{References}

1. Statistisches Bundesamt Deutschland (Edt.), Gesundheit: Ausgaben und Personal 2001 (Wiesbaden, 2003). http://www.destatis.de/presse/deutsch/pk/2003/gbe_2003.pdf (May 29, 2006).

2. Christiane Rosenow and Anke Steinberg, 10 Jahre bundeseinheitliche Krankenhausstatistik, in: Wirtschaft und Statistik 5/2002, edited by Statistisches Bundesamt Deutschland (Wiesbaden, 2002), pp. 383-391.

3. Martin Waiger, Flexible tarifliche Regelungen notwendig, $k u$-Sonderheft 04(7), 89 (2004).

4. Volker Großkopf and Michael Schanz, Bereitschaftsdienste im Krankenhaus, Die Schwester - der Pfleger 41(9), 776-784 (2002).

5. Bianca Reuter, Flexible Arbeitszeit im Wettbewerb, Der Arbeitgeber 52(1), 43-46 (2000).

6. Peter Knauth, Arbeitszeitflexiblisierung aus arbeitswissenschaftlicher Sicht, in: Arbeitszeitflexibilisierung im Dienstleistungsbereich, edited by Gert Zülch, Patricia Stock, and Thomas Bogus (Shaker Verlag, Aachen, 2002), pp. 51-74.

7. Patricia Stock, Thomas Bogus, and Sascha Stowasser, Auswirkungen flexibler Arbeitszeitmodelle auf den Personaleinsatz und die Belastungen des Personals (Shaker Verlag, Aachen, 2004).

8. Thomas Bogus, Simulationsbasierte Gestaltung von Arbeitszeitmodellen in Dienstleistungsbetrieben mit kundenfrequenzabhängigem Arbeitszeitbedarf (Shaker Verlag, Aachen, 2002).

9. Gert Zülch, Jörg Fischer, and Uwe Jonsson, An integrated object model for activity network based simulation, in: Proceedings of the 2000 Winter Simulation Conference, Volume 1, edited by Jeffrey A. Joines, Russel R. Barton, Keebom Kang, and Paul A. Fishwick (The Institute of Electrical and Electronics Engineers et al., Piscatawy, NJ, 2000), pp. 371-380.

10. Bernhard Teriet, Freie Arbeitszeitregelungen als Chance für Unternehmen und Mitarbeiter, in: Freie Arbeitszeit. Neue Betriebliche Arbeitszeitmodelle (Gottlieb Duttweiler-Institut, Rüschlikon, 1979). 
11. Gert Zülch, Patricia Stock, and Thomas Bogus, Working time recommendations for the load reduction of employees in retail stores, in: Human Performance and Aging, Proceedings of the XVth Triennial Congress of the International Ergonomics Association and The 7th Joint Conference of Ergonomics Society of Korea / Japan Ergonomics Society "Ergonomics in the Digital Age", Volume 4 (Ergonomics Society of Korea, Seoul, 2003), pp. 227-230.

12. Patricia Stock and Gert Zülch, Reorganising the Working Time System of a CallCentre with Personnel-oriented Simulation, in: Integrating Human Aspects in Production Management., edited by Gert Zülch, Harinder S. Jagdev, and Patricia Stock (Springer, New York, 2005), pp. 57-69.

13. Max-Jürgen Heitz, Ein engpaßorientierter Ansatz zur simulationsunterstützten Planung von Personalstrukturen (Dissertation, Karlsruhe, 1994).

14. Hans-Georg von Wedemeyer, Entscheidungsunterstützung in der Fertigungssteuerung mit Hilfe der Simulation (VDI-Verlag, Düsseldorf, 1989).

15. Sven Warnke, Entwicklung eines Systems computergestützter Planspiele zum Prozessmanagement im Krankenhaus (Lehrstuhl für Betriebswirtschaftslehre und Operation Research der Universität Erlangen-Nürnberg, 2001).

16. Uwe Jonsson, Ein integriertes Objektmodell zur durchlaufplanorientierten Simulation von Produktionssystemen (Shaker Verlag, Aachen, 2000). 